\title{
Scatter loss from environmental degradation of KDP crystals
}

\author{
E.K. Wheeler, J.T. McWhirter, P.K. Whiteman, C. \\ Thorsness, J. De Yoreo, I.M. Thomas, M. Hester
}

This article was submitted to the $31^{\text {st }}$ Boulder Damage Symposium: Annual Symposium on Optical Materials for High Power Lasers, Boulder, CO, October 4-7, 1999

\section{December 17, 1999}

U.S. Department of Energy

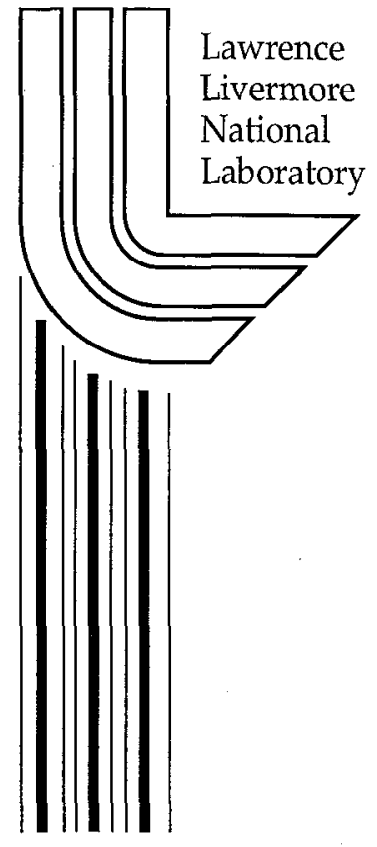




\section{DISCLAIMER}

This document was prepared as an account of work sponsored by an agency of the United States Government. Neither the United States Government nor the University of California nor any of their employees, makes any warranty, express or implied, or assumes any legal liability or responsibility for the accuracy, completeness, or usefulness of any information, apparatus, product, or process disclosed, or represents that its use would not infringe privately owned rights. Reference herein to any specific commercial product, process, or service by trade name, trademark, manufacturer, or otherwise, does not necessarily constitute or imply its endorsement, recommendation, or favoring by the United States Government or the University of California. The views and opinions of authors expressed herein do not necessarily state or reflect those of the United States Government or the University of California, and shall not be used for advertising or product endorsement purposes.

This is a preprint of a paper intended for publication in a journal or proceedings. Since changes may be made before publication, this preprint is made available with the understanding that it will not be cited or reproduced without the permission of the author.

This report has been reproduced directly from the best available copy.

Available to DOE and DOE contractors from the

Office of Scientific and Technical Information

P.O. Box 62, Oak Ridge, TN 37831

Prices available from (423) 576-8401

http://apollo.osti.gov/bridge/

Available to the public from the

National Technical Information Service

U.S. Department of Commerce

5285 Port Royal Rd., Springfield, VA 22161

http://www.ntis.gov/

OR

Lawrence Livermore National Laboratory

Technical Information Department's Digital Library

http://www.llnl.gov/tid/Library.html 


\title{
Scatter loss from environmental degradation of KDP crystals
}

\author{
E. K.Wheeler ${ }^{1}$, J. T. McWhirter ${ }^{2}$, P. K.Whitman ${ }^{1}$, C. Thorsness ${ }^{1}$, \\ J. De Yoreo ${ }^{1}$, I. M. Thomas ${ }^{1}$, M. Hester ${ }^{1}$ \\ ${ }^{1}$ University of California, Lawrence Livermore National Laboratory, \\ Livermore, California 94550, U.S.A. \\ ${ }^{2}$ Union College, Schenectady, New York 12309, U.S.A.
}

\begin{abstract}
Severe scattering losses from KDP crystals have been correlated with the exposure of porous sol AR coated crystals to ambient humidity. The scattering is attributed to formation of etch pits which develop under the coating on the KDP surface along crystallographic axes. This high angle scattering can in turn produce laser damage of downstream optics either through modulation of the beam or by optic contamination from ablation of adjacent metal structures.

We have developed a simple tool to characterize the evolution of scatter from sol-coated KDP surfaces. We have measured the rale of etch pil formation as a function of relative humidity and surface treatment using both microscopy and scaltering. We will discuss various surface treatments which can be utilized to retard or eliminate the environmental degradation of KDP crystals.
\end{abstract}

\section{INTRODUCTION}

For the National Ignition Facility (NIF) the electro-optical properties of potassium dihydrogen phosphate (KDP) crystals are exploited for two main purposes. First, in the Pockels cell KDP is used in the multipass amplifier architecture to switch the beam out of the main amplifier. Secondly, the light is frequency converted from a $1064 \mathrm{~nm}(1 \omega)$ wavelength to $351 \mathrm{~nm}(3 \omega)$ using a combination of potassium dihydrogen phosphate (KDP) and deuterated KDP (DKDP) crystals.

During the NIF prototype campaign on the Beamlet laser, large amounts of scattered light were generated by the KDP crystals, which were initially featureless and nearly scatter free. Upon microscopic examination of the crystals (Figure 1), voids in the KDP beneath the intact sol-gel coating were identified as the scattering sources. Light from a simple He-Ne laser $(\lambda=632 \mathrm{~nm})$ is visible out to a scattering half angle of over $40^{\circ}$ for some etch pits shapes.

Scattering is a concern for two main reasons: 1) the energy that reaches the target will be decreased and 2) the scattered light could cause collateral damage of other optics. Therefore, minimal scatter losses from the KDP are essential for high power use on the NIF.

\section{ETCH PITS ON SOL-GEL COATED KDP}

Surveying KDP crystals has revealed that etch pits are only present when a crystal is sol-gel coated. The morphology of the etch pits is determined by the plane of the cut relative to the crystallographic axes, as demonstrated in Figure 1. A Z-cut Pockels switch crystal develops square shaped etch pits beneath the sol-gel coating. Diamond shaped features occur on doublers with the long axis oriented perpendicular to the extraordinary crystal axis. For tripler crystals two cases exist. Long slits can develop that are approximately $40 \mu \mathrm{m}$ long, Figure 1d. These features act like a grating. Other tripler crystals have developed triangular or trapezoidal shaped pits. The transition from trapezoids to slits is under investigation. Based on transmission losses the scatter from etch pits is $4-8 \%$. Table 1 summarizes the characteristic length scales of the etch pits. 


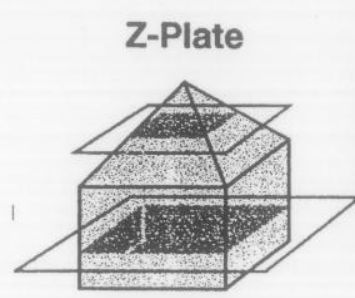

Doubler

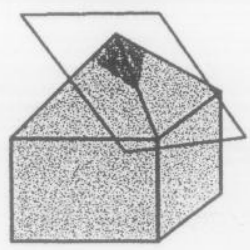

Tripler

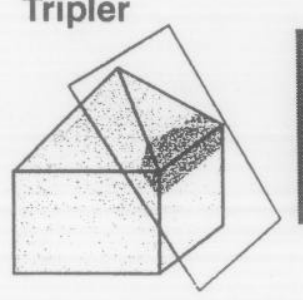

a

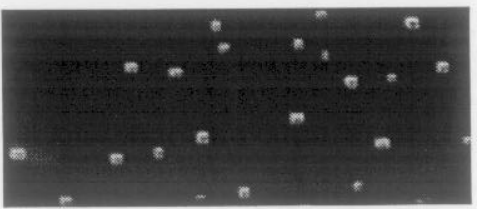

$20 \mu \mathrm{m}$

b

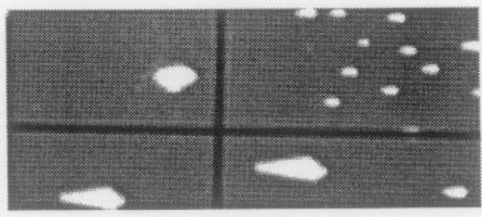

c

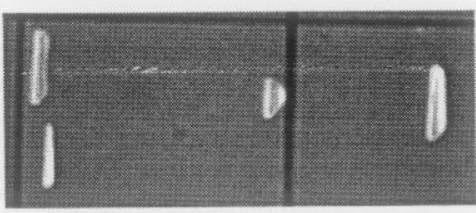

d

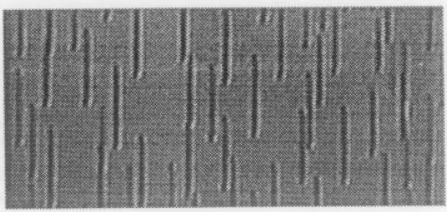

Figure 1: Optical microscopy of etch pits for various crystal cuts.

\begin{tabular}{|l|c|c|c|c|}
\hline Crystal Cut & $Z$ & Doubler & $\begin{array}{c}\text { Tripler } \\
\text { (trapezoids) }\end{array}$ & $\begin{array}{c}\text { Tripler } \\
\text { (slits) }\end{array}$ \\
\hline Length $(\mu \mathrm{m})$ & $1-2$ & $1-5$ & 3.5 & 40 \\
\hline Width $(\mu \mathrm{m})$ & $1-2$ & $0.5-2$ & 2 & 2 \\
\hline Depth $(\mu \mathrm{m})$ & - & $\mathrm{O}\left(10^{2}\right)$ & $120-310$ & $80-180$ \\
\hline
\end{tabular}

Table 1: Summary of etch pit dimensions.

Since etch pits occur under the sol gel coating, depths can not be directly determined using traditional means. For several doubler crystals the coating was removed by laser ablation to allow for atomic force microscopy (AFM) measurements. A typical AFM image and etch pit profile is shown in Figure 2. The facets correspond to the low energy planes of KDP. AFM indicates that the etch pits are self similar with the depth proportional to the $(\text { area })^{2 / 3}$. Therefore, the volume of an etch pit is related to its area raised to the $3 / 2$ power. This self-similarity is valid for doubler cut crystals over a range of etch pit sizes, Figure $2 \mathrm{c}$. These observations show that the pits are equilibrium structures. 

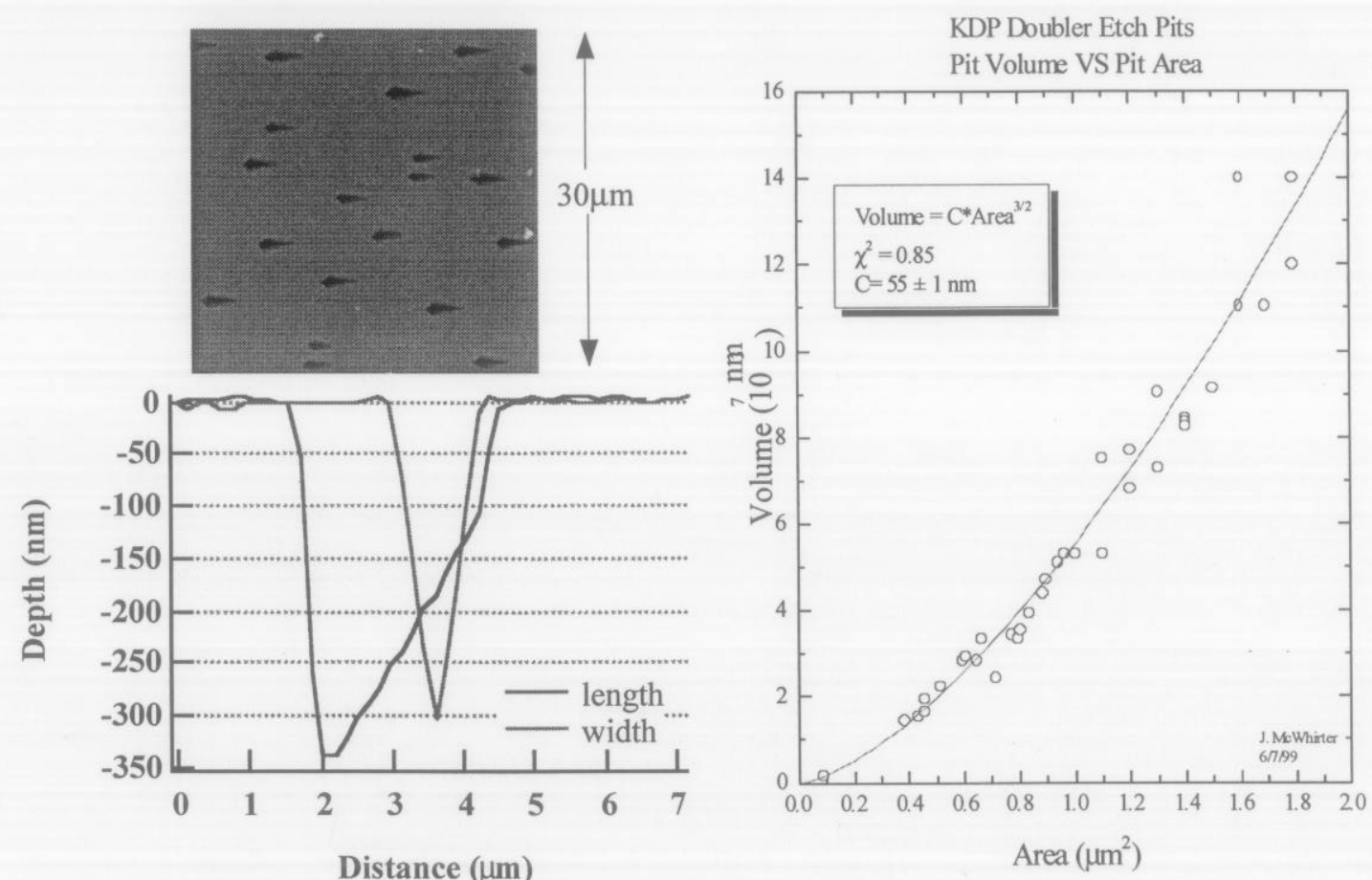

Figure 2: AFM image of etch pits on doubler crystal after laser ablating the coating, b) profile of etch pit along two axes and c) correlation between volume and area of etch pits over a range of sizes.

\section{PROPOSED MODEL}

It is hypothesized that etch pits form when the crystals are exposed to ambient humidity in a series of steps depicted in Figure 3. Water from the environment is absorbed into the porous sol-gel coating. Etch pits nucleate and grow as KDP is wicked up into the sol. Growth continues until the water reservoir in the sol is saturated with KDP. Etch pit size will be a function of the relative humidity (RH) that the crystal is exposed to. Factors controlling initiation are still being explored. It is important to note that coated crystals kept in a dry environment do not develop etch pits. More details of the model will be discussed in Section 6.

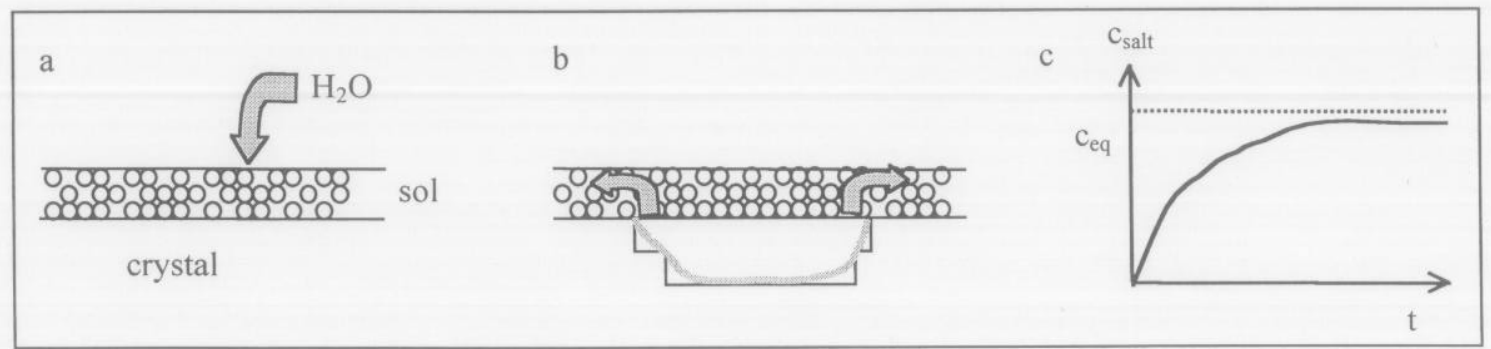

Figure 3: Proposed model for etch pit initiation and growth.

\section{EXPERIMENTAL DESIGN}

\subsection{Controlled humidity environments}

A series of crystals, cut from the same rapid growth KDP boule (RG8B) and single-point diamond-turned with a standard mineral oil-based process were subjected to a standard cleaning process before coating. The crystals were dip coated in solgel to form either a $70 \mathrm{~nm}$ or $210 \mathrm{~nm}$ thick coating $(3 \omega$ or $1 \omega)$. Control crystals were then placed in a dry desiccator. All crystals that were kept dry did not develop etch pits. Test crystals were stored in desiccators at the desired RH. Periodically the crystals were removed for both microscopy and scattering measurements (Figure 4). 
A simplified version of the light scattering apparatus is shown in Figure 4. Using a He-Ne laser $(\lambda=543 \mathrm{~nm})$ as the light source, the scattered light was collected with a focussing lens before reaching a power meter. This scattering data is limited by the collection angle of the focusing lens. For the data reported in the paper the scattering half-angles that are collected by the lens are $2^{\circ}<\theta<26^{\circ}$. This simple setup allowed semi-quantitative comparisons of the effect of different sol-gels, coating thicknesses, and surface treatments.

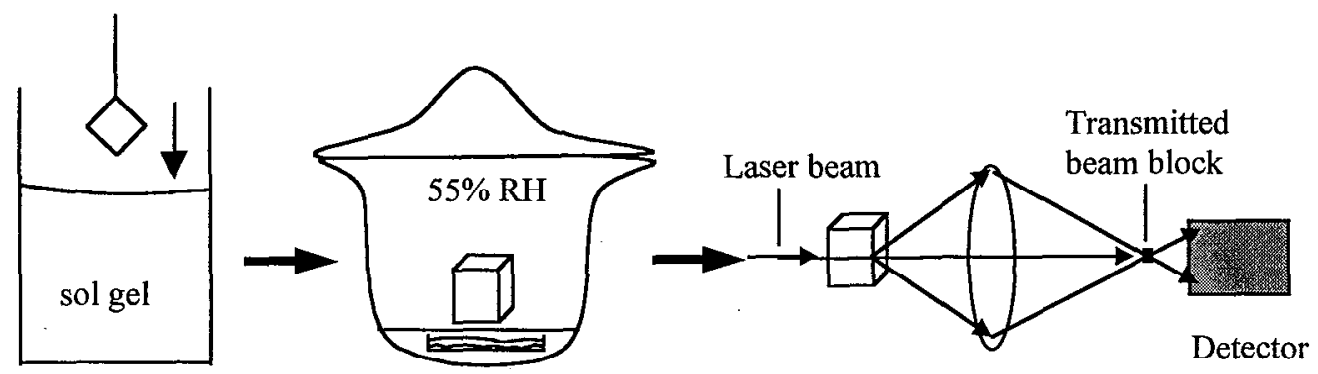

Figure 4: Experimental design for controlled environments.

\subsection{Light scattering and volume correlations}

In order to use light scattering to monitor the growth of the etch pits it was necessary to correlate the amount of scattered light with either the volume or area of the etch pits. The light scattered was measured at known locations on crystals that exhibited a wide range of etch pit sizes and number densities. The coating was then removed by laser ablation. After the coating was removed, AFM was used to determine the volume of etched KDP. Figure 5 shows a simple linear correlation between the scattering intensity and the volume of etched KDP within a given scan area.

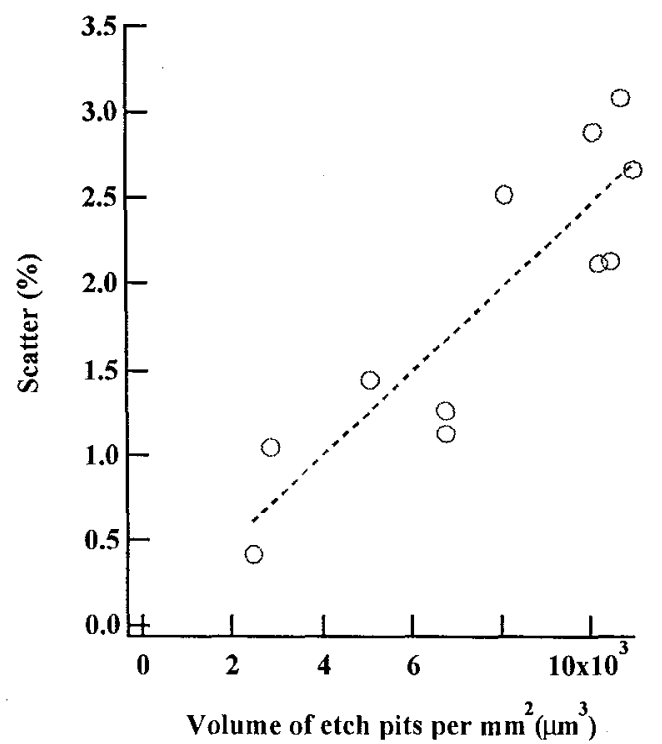

Figure 5: The light scattered correlates with the etched volume of $\operatorname{KDP}\left(\mu \mathrm{m}^{3}\right)$ per $\mathrm{mm}^{2}$ of surface.

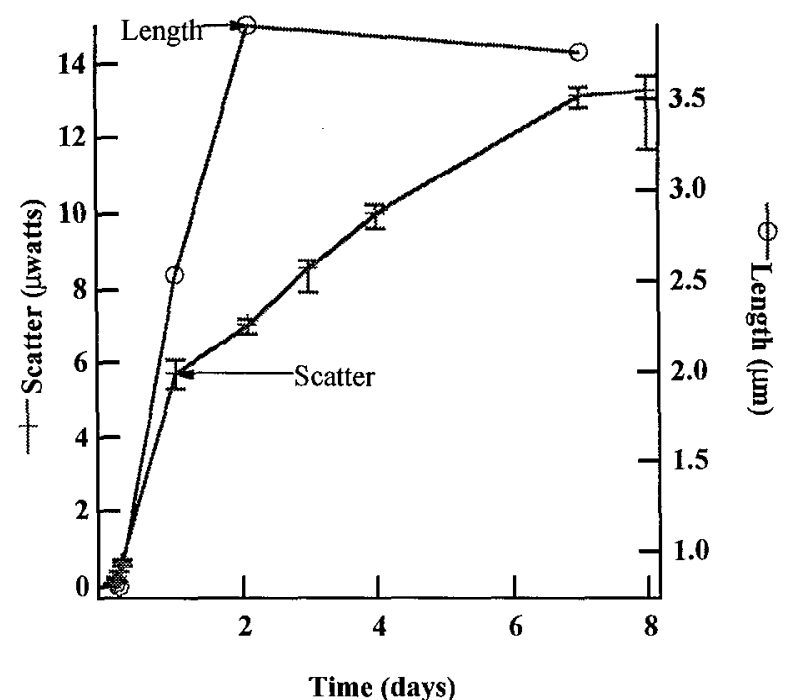

Figure 6: Microscopy and scattering can be used to monitor etch pit growth.

\section{RESULTS}

5.1 Growth of etch pits as monitored using microscopy and scattering

The evolution of etch pits can easily be monitored using both light scattering and optical microscopy. Etch pits can be detected after just 3 hours at $55 \%$ RH. At 2 days facets in the etch pits are easily observed. After just 48 hours the length of the etch pits does not change within the resolution of the optical microscope, Figure 6 . Scattering indicates that growth continues for approximately one week. 


\subsection{Diffusion limited transport}

Figure 7 shows equilibrium images of etch pits near surface defects (scratches). Etch pits nucleate preferentially along the scratch and leave a zone round the scratch that is depleted of etch pits. The size of the depletion zone increases with increasing RH. Note that the images in Figure $7 \mathrm{a}-\mathrm{c}$ are at different magnifications. As etch pits form preferentially along the defect, a salt plume is emitted into the sol. The diffusing salt plume drops the undersaturation in the sol-gel, effectively shutting off nucleation in the surrounding area. Because effective diffusion is an increasing function of water content in sol gel, higher humidity leads to wider denuded zones.

At higher RH, larger etch pits develop with a number density two orders of magnitude smaller than at $5 \%$ RH. Table 2 compares the characteristics of etch pits formed at three different relative humidities. As the RH increases, etch pit length and depletion zone size increase while the number density decreases. At $75 \% \mathrm{RH}$ the etch pit size distribution is bimodal with average sizes of 2.5 or $15 \mu \mathrm{m}$.
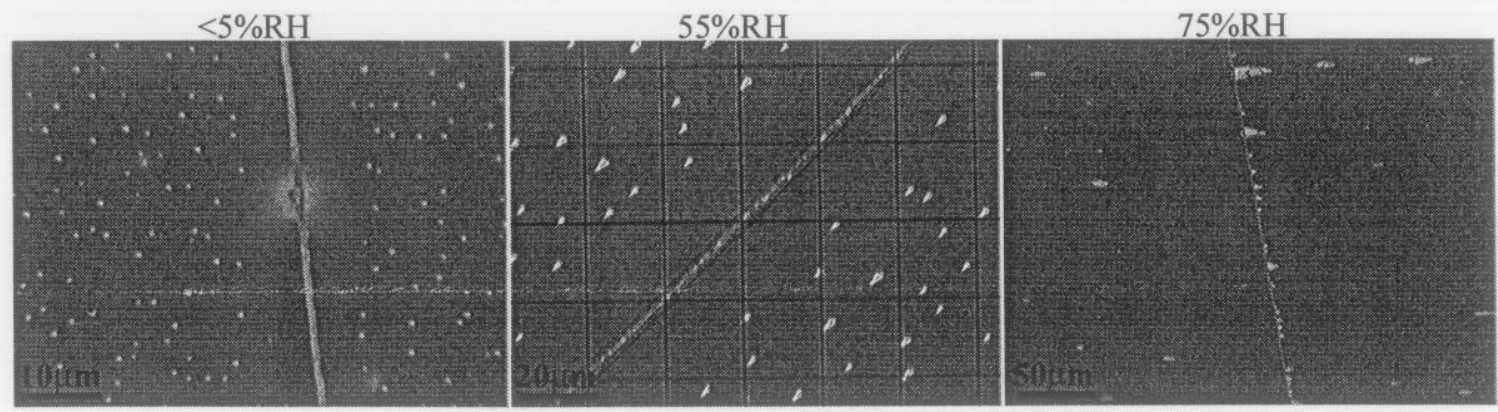

Figure 7: a) $\mathrm{RH}<5 \%$, b) $\mathrm{RH}=55 \%$, c) $\mathrm{RH}=75 \%$; depletion zones along surface defect increase with $\mathrm{RH}$.

From simple scaling arguments the size of the denuded zone indicates that the effective diffusivity is very small. At $55 \% \mathrm{RH}$ the effective diffusivity from scaling is $\sim 10^{-12} \mathrm{~cm}^{2} / \mathrm{s}$.

\begin{tabular}{|l|l|l|l|}
\hline Relative Humidity & $<5 \%$ & $55 \%$ & $75 \%$ \\
\hline Number density $\left(\right.$ per $\left.\mathrm{cm}^{2}\right)$ & $7 \times 10^{6}$ & $6.2 \times 10^{5}$ & $7.3 \times 10^{4}$ \\
\hline Average length $(\mu \mathrm{m})$ & 0.5 & 4.4 & 2.5 or 15 \\
\hline Denuded zone $(\mu \mathrm{m})$ & $\sim 6$ & $\sim 20$ & $\sim 55$ \\
\hline
\end{tabular}

Table 2: Effect of RH on number density, average etch pit length and depleted zone size.

\subsection{Preliminary in-situ kinetics}

An in-situ scattering measurement continuously measures the kinetics of etch pit growth. Humid nitrogen flows through a cell, which exposes just one surface of the crystal to a controlled humid environment. The surface of the crystal that is exposed to ambient conditions is not sol-gel coated. A He-Ne is directed through the center of the crystal allowing for scatter data to be collected continuously from the same location without removing the crystal from the humidity test. The scattering data in Figure 8 show the effect of RH on the kinetics of etch pit growth.

At $10 \%$ RH etch pits are not detectable after 1 week of exposure. Small etch pits are present after 2 weeks. With no temperature isolation for the cell, small fluctuations in room temperature influenced our measurements. These fluctuations seem to affect the alignment of some of our optics in the system causing cyclical fluctuations between two distinct states with different collection efficiencies. Modifications to the system have since eliminated this problem. However, the combination of these errors plus unidentified sample-to-sample variation make it difficult to differentiate either the kinetics or equilibrium scattering values at 55 and $75 \%$ RH.

The majority of etch pit growth occurs within four days of exposure at $\mathrm{RH} \geq 55 \%$. On average, for crystals exposed to $55 \% \mathrm{RH}$ or higher, etch pits begin to form within just a few hours. The two crystals at $55 \%$ in Figure 8 had slightly different kinetics. One was cut from the prism segment of the boule (RG8B) while the other was from the pyramid, which generally contains fewer atomically substituted trivalent impurities. At this point it is unclear whether the difference in kinetics is due to the impurity content or if this is just sample to sample variability. Part to part variability will be further explored using different techniques. 


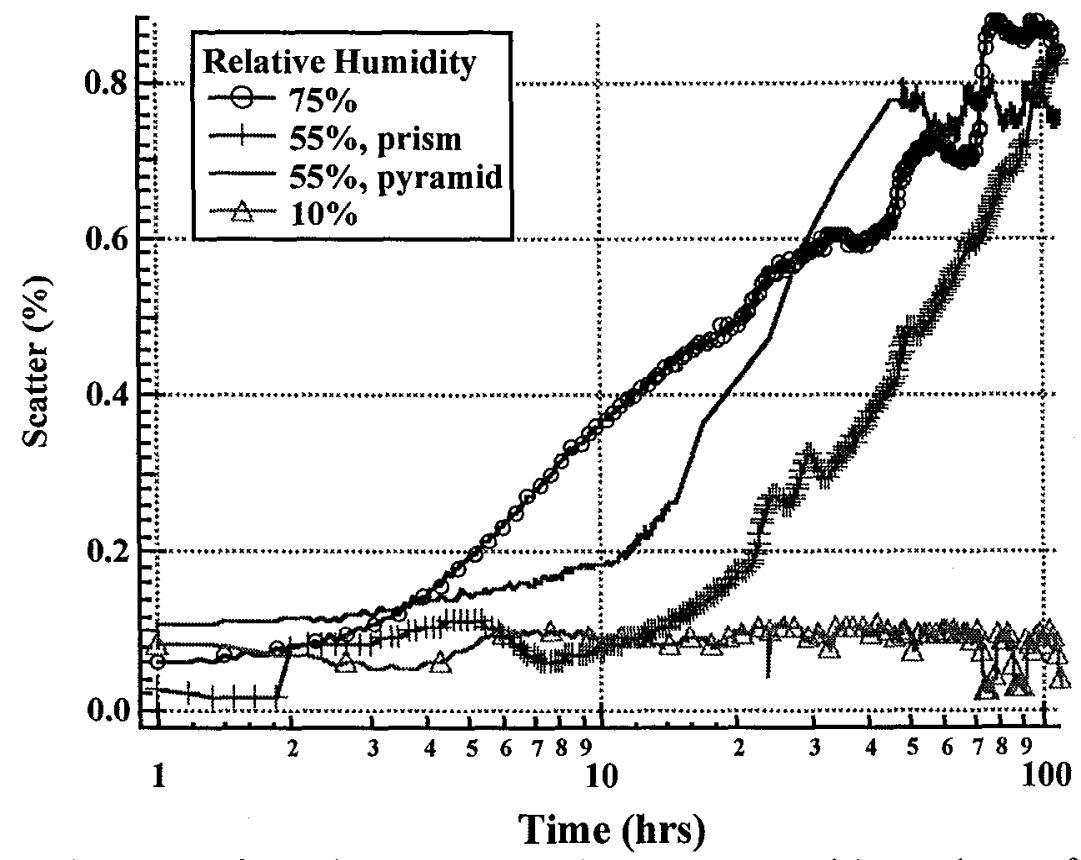

Figure 8: Growth of scattering at different humidities. Unless noted the samples were from the pyramid section of the boule.

\section{ENGINEERING MODEL}

As discussed in Section 3 the relative humidity is believed to control the effective salt diffusivity. The ambient RH first fills the microporosity in the sol gel. At low RH there are isolated pockets of water between the sol particles. In this situation transport of KDP from the surface is limited. Higher RH creates a network of water in the sol-gel, facilitating the removal of $\mathrm{KDP}$ and increasing the effective diffusion coefficient.

When the water contacts the KDP surface it is hypothesized that etch pits nucleate at a rate, $R_{N}$ :

$$
\mathrm{R}_{\mathrm{N}}=\mathrm{k}_{\mathrm{N}}\left(\mathrm{C}-\mathrm{C}_{\mathrm{s}}\right)^{\mathrm{n}}
$$

where $C$ is the local concentration of KDP in the water reservoir and $C_{s}$ is the concentration of KDP at saturation. Since the depleted zones imply that initiation is a strong function of undersaturation the nucleation rate is assumed to have a power law dependence on the undersaturation with $n \geq 1$. The nucleation coefficient, $k_{N}$, contains the material and surface-state dependent detachment energies.

The size of the depleted zones seen in Figure $7 \mathrm{~b}$ for $55 \% \mathrm{RH}$ scales to an effective diffusion coefficient on the order of $10^{-12} \mathrm{~cm}^{2} / \mathrm{s}$. Bulk diffusivity of KDP in watcr is $10^{-5} \mathrm{~cm}^{2} / \mathrm{s}$. Preliminary experiments resulted in $D_{\text {eff }} \sim 1 \times 10^{-12} \mathrm{~cm}^{2} / \mathrm{s}$ at $55 \% \mathrm{RH}$, verifying that diffusion of KDP in the sol is the limiting step and suggesting that the diffusion is hindered by being through the microporosity. Because the diffusion coefficient of KDP in water through the sol is orders of magnitude smaller than the dissolution rate of the KDP, etch pit growth rate, $\mathrm{R}_{\mathrm{G}}$, is diffusion limited.

$$
\mathrm{R}_{\mathrm{G}}=\mathrm{k}_{\mathrm{G}}\left(\mathrm{C}-\mathrm{C}_{\mathrm{s}}\right)
$$

The transport coefficient, $\mathrm{k}_{\mathrm{G}}$, is a function of the effective diffusivity and pit spacing.

Figure 9 shows predicted trends in the maximum radius with transport coefficient, $\mathrm{k}_{\mathrm{G}}$. Simply changing $\mathrm{k}_{\mathrm{G}}$ results in a wide range of maximum radii for etch pits. The corresponding effective diffusivity for the lowest value of $k_{G}$ is on the same order of magnitude as the preliminary measurements of $D_{\text {eff }}$ at $55 \%$ RH. A lower $D_{\text {eff }}$ results in a smaller average pit size and a much longer equilibration time than a larger $D_{\text {eff. }}$. This agrees with the observed trends in relative size of etch pits versus relative humidity (Table 2). The engineering model also predicts larger number densities at lower $\mathrm{k}_{\mathrm{G}}$. Both of these trends are in agreement with experimental observations. 


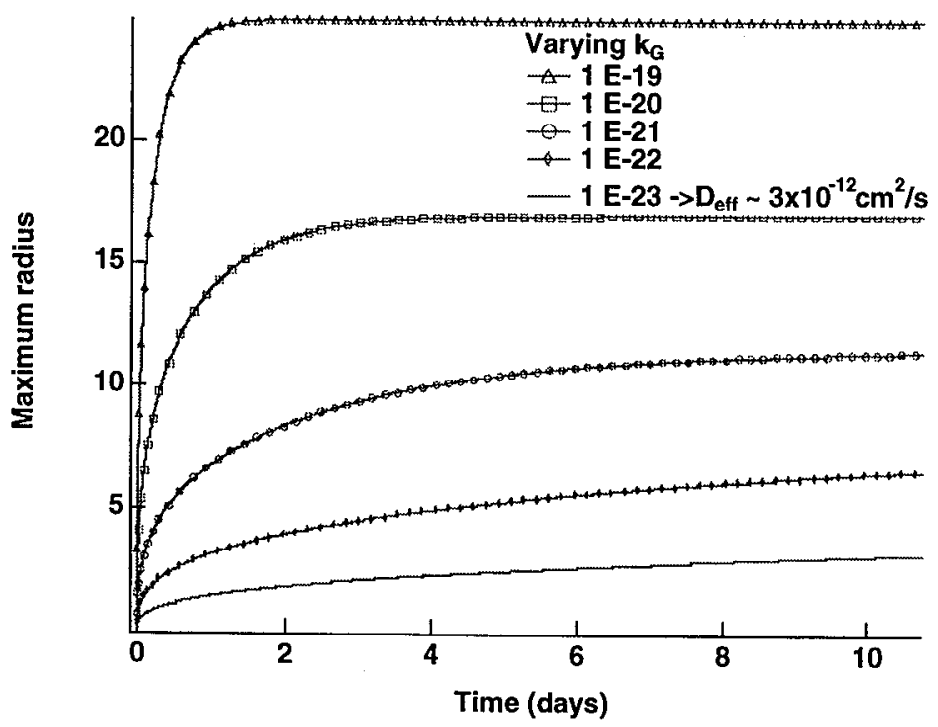

Figure 9: Engineering model predictions for the growth of etch pits.

\subsection{Doublers}

\section{MITIGATION SCHEMES}

For doubler cut crystals etch pit mitigation has been accomplished by preventing $\mathrm{H}_{2} \mathrm{O}$ transport to the surface with a barrier coating. NOVA KDP crystals had a thermally cured silicone coating under the standard sol-gel antireflective coating. After 9 years at ambient humidities there were no etch pits.

Thermal annealing the crystal after diamond turning delays the onset of etch pits, but does not prevent their formation. 'The etch pits were smaller with a much higher number density. Scatter from annealed surfaces is approximately 3 times lower than for an unannealed surface, Figure 10.

Preliminary screening of polymethylmethacrylate (PMMA) as a protective barrier resulted in no etch pits after 1 month at 55\%RII. However, thermal silicone is the preferred material for doublers because its lower index (1.42 vs. 1.49 for PMMA) has optical benefits for broadband coatings. ${ }^{2}$

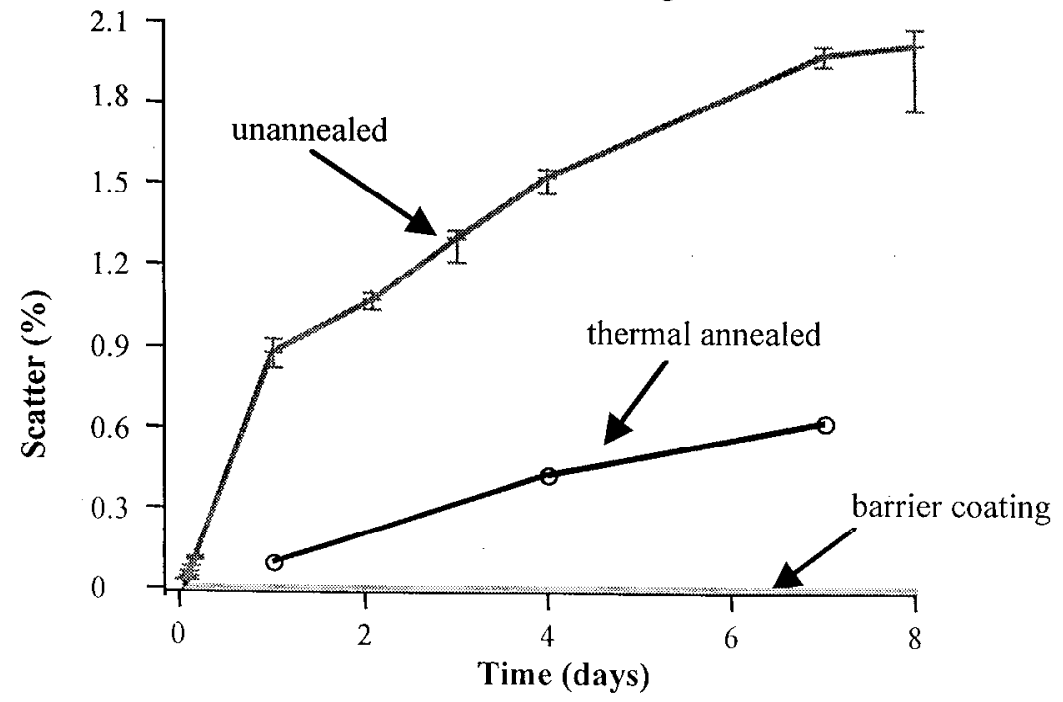

Figure 10: Comparison of scattering for unannealed and annealed crystals, and a crystal with a barrier coating beneath the standard sol-gel. 


\subsection{Triplers}

DKDP is not stable at the temperature of the thermal anneal for the silicone barrier layer used on doubler crystals. PMMA coatings have not yet demonstrated sufficiently high $3 \omega$ damage threshold to be used on tripler output surfaces. Therefore, etch pit mitigation for DKDP tripler crystals is focusing on changing the chemistry of the sol to reduce transport.

Hydrophobic sols have been prepared by reacting the polar surface silanol groups with hexamethyl-disilizane (HMDS) in ethanol solution. The resulting non-polar trimethyl siloxyl groups produce a hydrophobic sol coating, as shown in Figure 11.

DKDP crystals from rapid growth boule BD7 were coated with HMDS-treated, deammoniated sols and showed no etch pits after 3 weeks at $55 \% \mathrm{RH}$. Initial measurements of $1 \omega$ coatings made from HMUS sol in heptane resulted in unacceptable scattering, although it did not increase with exposure. The high baseline scatter can be attributed to flocculation of the sol. Refinement of the HMDS treatment procedure has reduced this initial scatter to below the detection limit of our apparatus, Figure 12. HMDS treated sol-gels have repeatedly prevented the formation of etch pits.
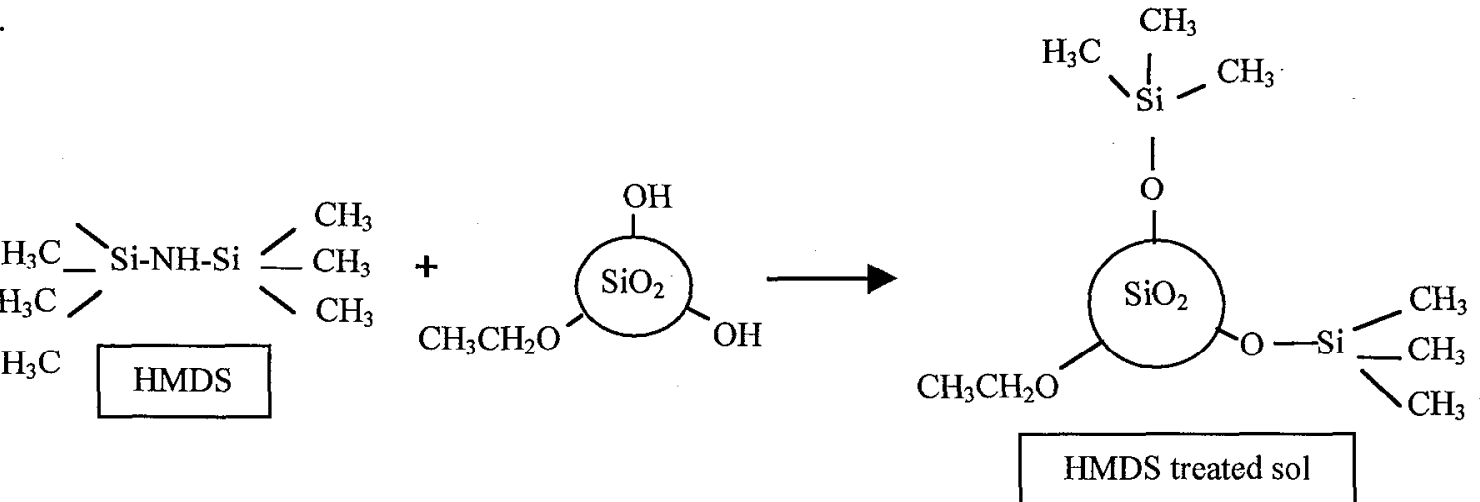

Figure 11: Reaction of polar surface silanol (Si-OH) groups with hexamethyldisilizane (HMDS) to produce hydrophobic HMDStreated sols.

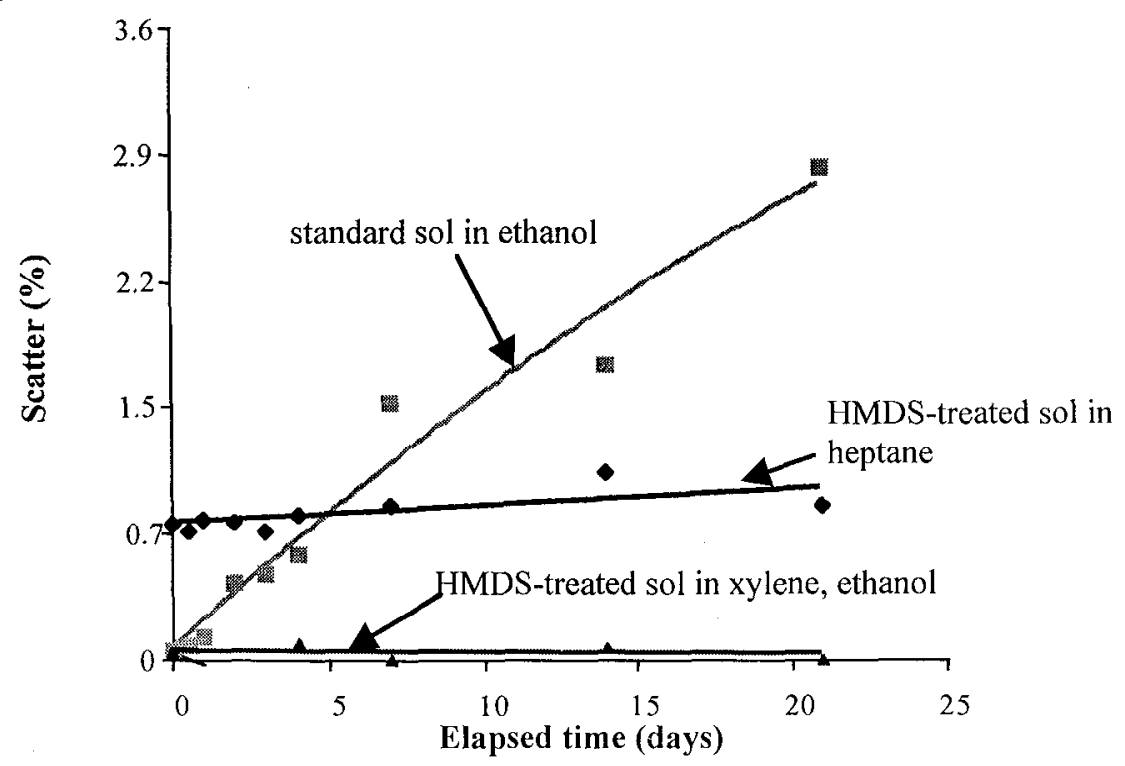

Figure 12: Scatter from the HMDS-treated sol in xylene or ethanol is below the detection limit of the apparatus. 


\section{SUMMARY}

After exposure to ambient humidity, sol-gel coated KDP crystals form etch pits. The etch pits are voids in the crystal beneath the intact coating. Water from the atmosphere is absorbed into the porous coating. When the water contacts the KDP it etches the surface. The morphology of the etch pit is determined by the crystal cut. The etch pit continues to grow until the reservoir of water in the sol gel is saturated with KDP. The diffusion of KDP from the edge of the pit into the bulk sol-gel is the rate limiting step.

Scattering has proven a quick, inexpensive, simple method to detect the presence of etch pits on KDP and DKDP crystals. Since scattering correlates to the total volume of etched KDP it can be used to validate a simple engineering model of etch pit nucleation and growth.

Thicker coatings yield higher equilibrium scattering values. This is consistent with thicker coatings absorbing larger volumes of water, and thus higher equilibrium volumes of KDP. Higher relative humidities produce larger etch pits but in lower densities. Preliminary kinetics data at 55\% RH indicate that etch pits nucleate within the first few hours of exposure. After 2 weeks at $10 \%$ RH small etch pits are visible. These results are consistent with an effective diffusivity that is dependent on the fraction of sol void which is filled with water. Variability from sample to sample still needs to be resolved, but the simple diffusion-limited growth model gencrally agrees with the observed trends. Work on the model is ongoing. Future experiments will allow further refinement of the engineering model and determination of the controlling nucleation and growth coefficients.

Two different mitigation schemes are in progress. For doublers, thermally-cured silicone coating prevents etch pits from developing. For triplers, changing the chemistry of the sol to reduce water absorption and hence reduce transport is the second promising method to eliminate etch pits. Further development of treated sols is currently being pursued.

\section{ACKNOWLEDGEMENTS}

*Work performed under the auspices of the U. S. Department of Energy by Lawrence Livermore National Laboratory under Contract No. W-7405-ENG-48.

\section{REFERENCES}

1. R. C. Reid, J. M. Prausnitz, B. E. Poling, The Properties of Gases \& Liquids, McGraw Hill, San Francisco, 1987.

2. I. M. 'Thomas, "High laser damage threshold porous silica antireflective coatings," Appl. Opt. 25, pp.1481-3, 1986. 